\title{
Humanização do Cuidado em Saúde: \\ DE TECNICISMOS A UMA ÉTICA DO CUIDADO
}

\author{
Maria Elizabeth Barros de Barros $\star$ \\ Rafael da Silveira Gomes ${ }^{\star}$
}

\begin{abstract}
RESUMO
O cuidado em saúde tem sido um tema bastante debatido. Muitas são as noções e concepções propostas. A produção sobre o tema é numerosa e a demanda por um "cuidado humanizado" é recorrente. O texto propõe analisar o "cuidado humanizado em saúde" a partir da problematização das noções de humano, saúde e cuidado, bem como das práticas de saúde. Propõe uma noção de cuidado que emerge no encontro entre os diferentes atores que habitam os serviços de saúde, numa relação em que o outro é percebido como legítimo, fundando uma clínica transdisciplinar, que produz desvios, sujeitos e modos de vida.
\end{abstract}

Palavras-chave: cuidado; saúde; humanização; clínica transdisciplinar.

\section{HumANizATION OF HEALTH CARE: \\ FROM TECHNICALITIES TO AN ETHICS OF CARE}

\begin{abstract}
Health care has been the theme of several debates and there many different ideas related to it. There are many productions towards this topic and the demand for a "humanized health care" is strong. This paper analyzes the "humanized health care" questioning the ideas of human, health and care, as well as the practices in health. We propose an idea of health care which emerges in the encounter of the different actors who attend health centers, in a relationship where the other is understood as a legitimate, founding a transdisciplinary clinic that produces deviations, changes, subjects and ways of life.
\end{abstract}

Keywords: care; health; humanization; transdisciplinary clinic.

\footnotetext{
^ Professora titular da Universidade Federal do Espírito Santo. consultora da Secretaria de Atenção à Saúde do Ministério da Saúde. End.: Universidade Federal do Espírito Santo, Centro de Ciências Humanas e Naturais, Departamento de Psicologia. Av. Fernando Ferrari, s/n, Goiabeiras - Vitoria, ES - Brasil. CEP: 29060-900.

E-mail: betebarros@uol.com.br

$\star \star$ Professor da Universidade Federal do Espírito Santo. End: Universidade Federal do Espírito Santo, Centro de Ciências Humanas e Naturais, Departamento de Psicologia. Av. Fernando Ferrari, s/n, Goiabeiras - Vitoria, ES - Brasil. CEP: 29060-900.

E-mail: rsgomes33@hotmail.com
} 


\section{INTRODUÇão}

Nos últimos anos, a saúde tem sido recorrente tema de debate nos mais diversos setores da população brasileira. Jornais, revistas e televisão apontam ora as mazelas dos serviços, a lotação dos hospitais, o preço dos planos de saúde; ora as inovações tecnológicas, os milagres da Medicina. Em meio a esse debate, uma ampla parcela da população que utiliza os serviços de saúde, sejam eles da rede pública, sejam da rede privada, não obstante a diferença existente entre ambos, se queixa da "falta de cuidado" com que tem sido tratada. Eis algo que podemos apontar como um claro paradoxo: embora o cuidado tenha posição de destaque no campo da saúde, chegando a ser proposto como seu objeto (MEHRY, 2003), há um desconforto difuso gerado pela percepção de sua ausência nos serviços de saúde. Mas, trata-se mesmo de sua ausência? Do que estamos falando, quando usamos a expressão "cuidado em saúde"? Como têm se efetivado as práticas de cuidado em saúde?

Este texto se construiu, então, diante dos desafios colocados por essa temática considerando-se sua importância indiscutível para o campo da saúde. O caminho realizado teve oo objetivo de abrir outras linhas problemáticas nesse debate, entre as formulações de Campos (2003), Ayres (2001, 2007), Teixeira (2003), Luz (2001, 2003), Mehry (2003), Boff (2003) e da Política Nacional de Humanização (PNH) (BRASIL, 2004), que destacam as interfaces cuidado e gestão nos serviços de saúde ou, mais precisamente, sua indissociabilidade.

$\mathrm{Na}$ leitura dessas formulações teóricas, deparamo-nos com uma tendência, ou melhor, com uma exigência: a de um cuidado "humanizado", que nos coloca, imediatamente, frente ao desafio de problematizar o conceito de Humano formulado nesse modo de colocar o problema.

Este texto alia-se à proposta da PNH (BRASIL, 2004) que preconiza uma concepção de homem que se constitui no concreto da experiência nas lutas cotidianas, numa direção ético-política que opõe "O Homem" a "um homem", a todos nós, buscando resistir a esse Homem ideal, muitas vezes presente nos discursos no campo da saúde (SANTOS-FILHO; BARROS; GOMES, 2009). Assim, a concepção de humano com o qual trabalhamos subverte "O Homem" como metro padrão ou idealidade a partir do qual se modela a existência humana. (BENEVIDES; PASSOS, 2005). Uma prática de cuidado humanizada, a partir da Política Nacional de Humanização, teria como direção processos de subjetivação que se efetivam como alteração dos modelos de gestão e de cuidado em saúde, produção de novos sujeitos e novas práticas, tomando a vida em seu movimento de produção de normas e não de assujeitamento a elas (BENEVIDES ; PASSOS, 2005). Esta é uma tarefa sempre inconclusa, aa reinvenção de nossa humanidade, que se faz com um trabalho constante de produção de outros modos de vida, de novas práticas de saúde, de outros modos de cuidar. 
Dessa forma, o cuidado em saúde precisa ser considerado a partir dessa complexidade, pois muitos são os ângulos de aproximação e discursos possíveis sobre essa questão. Uma vez que a noção de cuidado é polissêmica e transita por diferentes abordagens conceituais e metodológicas, cabe perguntar o sentido que adota nos diferentes contextos e quais são os efeitos produzidos por elas.

Para além de uma idéia transcendente, em que se luta para atingir um objetivo, propõe-se uma noção decuidado que recusa os binarismos ou dualismos que opõem cuidado a descuidado, ou a ausência de cuidado, e opta-se por tomá-lo a partir da noção de devir. Devir, não no sentido de busca de um ideal - o que manteria a discussão numa dimensão transcendente - mas como um acontecimento que se dá no decorrer do seu próprio processo. $\mathrm{O}$ cuidado se produz no próprio ato de cuidar, ele não é antecipável, ele é coemergente às relações que se estabelecem e avaliado por seus efeitos, pela potência que produz naqueles que o compartilham.

No entanto, a não existência de um sentido definitivo do que seja cuidado não deve ser entendida como fragilidade. Ao contrário, a falta de uma definição é potencialidade, na medida em que abre um campo de possíveis para a construção de sentidos diversos e mais oportunos para operarmos no campo da saúde. A imanência das práticas de cuidado permite sua construção diária no engendramento das diversas forças presentes no campo social. É essa aversão às formas, típica da imanência, que permite que ela se atualize, se integre e se diferencie em seus efeitos (DELEUZE, 1988).

Por outro lado, problematizaro cuidado no âmbito da saúde, exige colocar em análise o próprio conceito de saúde. Se, em relação à temática do cuidado encontram-se várias formulações, não é diferente no que diz respeito ao conceito de saúde, uma vez que saúde é, a priori, um objeto complexo, portanto, multifacetado, plural, podendo gerar inúmeros discursos a partir dos diferentes pontos de vista; é plural em olhares e significações (ALMEIDA FILHO, 1997). Conforme expõe Luz (2001), essa pluralidade está presente tanto nas representações, modelos e discursos, como no mercado social da saúde.

Então, diante de um objeto multifacetado e intrinsecamente dinâmico como a saúde, procuramos tangenciá-lo a partir de concepções que abarquem a mobilidade inerente às relações humanas travadas cotidianamente. A teoria vitalista de Canguilhem (2000) contribui para o debate, uma vez que apresenta uma concepção de saúde diferente da tradição biomédica, essencialmente biológica e unicausal, que a restringe a um estado estático de ausência de doença. A concepção de saúde desse autor, funda-se numa concepção ativa da vida, na atividade incessante dos seres para manterem-se vivos, experiência que não exclui acidentes ou mesmo a doença. "A vida procura ganhar a morte, em todos os sentidos da palavra ganhar e, em primeiro lugar, no sentido em que o ganho é aquilo adquirido por meio do jogo. A vida joga contra a entropia crescente" (CANGUILHEM, 2000, p. 208).

A vida é, então, este constante jogo, esta luta contra a entropia, ${ }^{1}$ que, em último estágio, significa a morte do ser vivo. Nesse sentido, saúde é luta dinâmica, ou melhor, é possibilidade de lutar contra a doença, que é entendida como a incapacidade ou a impossibilidade de lutar. O estado de saúde não é um estado puro e 
estático, incompatível com a doença. Ao contrário, trata-se de um estado em que a idéia da doença é uma constante. Um homem saudável não é aquele para o qual não existe a possibilidade da doença, visto que esse homem não existe, mas aquele que, em contato com a doença, consegue frear um processo que em outro ser humano poderia levar à morte. "O homem são não é, portanto, são. Sua saúde é um equilíbrio conquistado à custa de rupturas incoativas. A ameaça da doença é um dos elementos constitutivos da saúde" (CANGUILHEM, 2000, p. 261).

Dejours (1986), seguindo esse mesmo caminho, faz uma crítica à concepção internacional de saúde da OMS, que a descreve como um estado de bem-estar físico, mental e social. Essa conceituação leva-nos a pensar a saúde como um estado estático, que poderíamos atingir e manter. No entanto, para esse autor, o "estado de saúde não é certamente um estado de ausência de movimento, de conforto, de bem-estar e de ociosidade. É algo que muda constantemente" (DEJOURS, 1986, p. 8). A concepção de saúde tem que levar em consideração a variabilidade inerente aos seres humanos, tem que levar em consideração a diversidade dos humanos.

Além da variabilidade humana, temos que ressalvar as constantes alterações do meio em que habitamos e que produzimos. É importante entender que essa relação não é determinista, ou seja, a saúde não é um resultado determinado pelo meio, mas a saúde é vivida nas relações homem e meio, relações em que não há passividade ou subjugação.

Segundo Maturana e Varela (1995), o que caracteriza os seres vivos é o fato de produzirem continuamente a si mesmos a partir de suas interações com um meio que também se produz nesse processo. Essa produção efetiva-se mediante a organização contemporânea da unidade autopoiética a partir da qual será definida a qualidade das relações dinâmicas estabelecidas para manter-se adaptada. Adaptação entendida como o resultado de um acoplamento com o meio e não como resposta às suas exigências. Cada ser vivo:

classifica e vê suas contínuas interações com o meio de acordo com sua estrutura a cada instante, que por sua vez está em contínua mudança devido sua dinâmica interna. $\mathrm{O}$ resultado geral é que a transformação ontogênica não cessa até a sua desintegração (MATURANA; VARELA, 1995, p. 112).

A desintegração é, então, a morte, a imobilidade é a morte; enquanto há vida, há mudança. A vida é exatamente a possibilidade de mudança, de autocriação (autopoiese) neste confronto incessante. A história de um ser é a história de suas articulações com o meio e é isso que determina seu modo de ser no mundo e o próprio mundo. A vida seria então essa relação arriscada com o que nos circunda, e a saúde deveria ser entendida não como a subordinação passiva ao meio, mas como o empreender, o atuar nele, construindo-o. A saúde seria um estar dinâmico na vida, sempre singular, um estado que não corresponde à ausência de doenças. Ao contrário, nessa perspectiva, está relacionada com a capacidade de enfrentá-las e de expandir as condições de vida, processo que se dá mediante a interação em que homem e meio se transformam simultaneamente, num processo de coengendramento. 
Diante disso, a saúde é pensada como "margem de segurança" (CANGUILHEM, 2000). Assim, ao se falar de saúde deficiente, estamos falando de uma restrição da margem de segurança. Essa restrição seria resultado da diminuição da tolerância e do poder de reagir em frente às agressões do meio. A partir dessa noção, a saúde poderia ser definida pela possibilidade de cada um enfrentar as situações novas e as infidelidades do meio que constituem nossa história (CAPONI, 1997).

A saúde não é, então, a ausência de doença, mas a:

possibilidade e a capacidade que um grupo tem na sociedade para controlar e dirigir individual e coletivamente seus processos vitais, sua forma de viver [...] não interessa lutar para prolongar a vida ou para erradicar as doenças, sem ter a possibilidade de decidir de que queremos adoecer e de que queremos morrer (NORIEGA, 1993, p.169).

Pensada a partir de uma perspectiva em que a relação homem-meio seja focalizada - o homem atua no meio, luta contra suas infidelidades e não é determinado por ele; homem e meio relacionam-se, transformam-se e produzem-se. Diante disso emergem algumas questões: o meio resultante das relações que estabelecemos tem nos permitido privilegiar a produção de saúde ou de doença. Qual/ quais saúde/saúdes estamos produzindo nessa relação/construção?

\section{CUIDAdO: QUAIS MOdOS PRODUZIR NAS PRÁTICAS EM SAÚDE?}

Diante do exposto, podemos dizer que a saúde é produzida no próprio viver, é o resultado de um processo de construção de si e do mundo, é estar na vida com o outro, construída na alteridade. Alteridade como experiência da existência do outro, não como objeto, mas como um outro sujeito, co-presente no mundo das relações intersubjetivas.

É neste momento que ressalta-se um primeiro atravessamento entre saúde e cuidado. A própria idéia de cuidado aponta uma forma de relacionar-se e constituir-se no e com o mundo, "é um modo de ser-no-mundo que funda as relações que se estabelecem com todas as coisas" (BOFF, 2003, p. 92). Para esse autor, o cuidado se contrapõe a uma relação com o mundo que se caracteriza pelo estabelecimento de uma relação hierarquizada com o meio, fundamentada numa visão antropocêntrica, na qual o homem seria superior à natureza e caberia, a ele intervir sobre ela e dominá-la. Partindo dessa perspectiva, o homem se valeu da razão analítica como instrumento balizador de sua empreitada de dominação da natureza. Isso propiciou uma "objetivação" do mundo, que foi acentuada com a revolução científica e a ascensão da ciência moderna (OLIVEIRA, 2001).

Essa tem sido a postura utilizada como estratégia para afirmação do discurso médico oficial, para a manutenção de sua hegemonia em detrimento de outros discursos sobre a doença. Várias foram, e continuam sendo, as estratégias utilizadas para conservar a relação médico-paciente assimétricas (BOLTANSKI, 
1984), que vão desde a forma de (não) se comunicar com o paciente, de negar ou desqualificar seus conhecimentos sobre sua saúde; até a utilização de procedimentos técnicos e tecnológicos que acentuam sua posição de objeto:

O doente nu, deitado, imóvel e silencioso é, realmente, objeto das manipulações físicas do médico, que, vestido, de pé e com seus gestos livres, ausculta-o ou apalpa-o, ordenalhe que se sente, que estenda as pernas, pare de respirar ou tussa (BOLTANSKI, 1984, p. 57).

Conforme Luz (2003), nessa relação em que o paciente é objetificado pelo profissional de saúde subtrai-se, além de seu corpo e de seu psiquismo, símbolos, significados pessoais e sociais sobre o seu processo de adoecimento, menosprezando a importância do aspecto simbólico para a realização do tratamento.

Reafirmando esse processo de "objetificação" do outro, Foucault (1995, 2002) aponta que a Medicina moderna se caracteriza como uma estratégia de poder disciplinar, além de biopolítico, que tem nos corpos de cada indivíduo e da população seu foco de atuação e de exercício de poder, buscando torná-los úteis e dóceis. Poder que é garantido pelo discurso científico do médico, compatível com o regime de verdade da nossa sociedade, e por essa série de técnicas microfísicas - que buscam gerir "gestos, atitudes, comportamentos, hábitos, discursos" (MACHADO, 1995, p. 12).

Tais características ultrapassam o âmbito do consultório médico, da relação médico-paciente e se reproduzem nas diferentes esferas das práticas de saúde "esse tensionamento relacionado à dificuldade em lidar com a alteridade [...] está, na verdade, instalado no coração do desenvolvimento tecnocientífico da moderna biomedicina" (TEIXEIRA, 2003, p. 93). Essas práticas se alastraram pelos diversos setores dos serviços de saúde e são reproduzidas por muitos profissionais no cotidiano dos serviços.

No entanto, é fundamental ressaltar que se faz referência, aqui, àracionalidade biomédica, e não àspráticas médicas de forma generalizada, ainda que aquela tenha expressões claras e extensas nestas. Também não cabe, neste momento, generalizar seus praticantes. É importante frisar que grande parte das críticas feitas à Biomedicina teve o próprio meio médico como fomentador:

a divisão do corpo humano, a tecnologização das práticas e a fragmentação do saber, com o surgimento das várias especialidades médicas, têm gerado reações contra a expropriação da saúde e, desde a década de 1970, vêm propiciando um movimento que busca ressuscitá-la como objeto científico (COELHO; ALMEIDA FILHO, 2002, p. 316).

É nesse campo de forças que emerge a proposta de pensar o cuidado a partir de outras diretrizes, como uma clínica ampliada, formulada pela Política Nacional de Humanização, pois, no momento em que se fala de uma crise da saúde (AYRES, 2001), a Política Nacional de Humanização se constrói como uma 
proposta para a superação do reducionismo ao qual a racionalidade biomédica ocidental está aprisionada. $\mathrm{O}$ estabelecimento de uma relação com o outro em que este não é transformado em objeto é imprescindível. É na tentativa de superação da "cisão eu-outro" (TEIXEIRA, 2003) e da construção de uma relação sujeitosujeito que estamos propondo práticas de cuidado.

\section{A racionalidade biomédica: SOBRE ALGUNS USOS DO "CUIDADO"}

É sob a sombra do modo-de-ser técnico-científico que se situa a prática biomédica moderna. As práticas de saúde, principalmente a praticada no último século, são marcadas fortemente pela objetificação do outro; pela fragmentação do corpo humano e pela especialização dos saberes sobre ele, pelo distanciamento e pela intermediação tecnológica da relação médico-paciente - reafirmando os ideais científicos de neutralidade e objetividade. Como afirma Luz (2003), o paradigma que fundamenta a Medicina na contemporaneidade afastou de suas investigações diagnósticas e intervenções o sujeito. Como aponta Camargo Jr. (2003), muitas vezes o desprezo ao sofrimento do sujeito ocorre porque o médico estabelece a relação com a doença. O paciente é somente o meio de acessá-la e deve ter seus comentários evitados, uma vez que ele é recorrentemente entendido como fonte de distorções.

Muitos são os relatos que corroboram com essa afirmação e apontam a insatisfação da população, que fala de uma "falta de cuidado" no que se refere aos serviços de saúde. A racionalidade médica ocidental esqueceu-se de que também era uma arte curar sujeitos e restringiu-se a um saber científico, baseado em diagnósticos cada vez mais precisos em detrimento da prática terapêutica, da cura e do cuidado (LUZ, 2003). Conforme Foucault (1998), a racionalidade médica que emerge nos fins do século XVIII dá ao olhar uma outra dimensão, encerra na percepção da tessitura das coisas e de sua aparência a face primeira da verdade. "O espaço da experiência parece identificar-se com o domínio do olhar atento, da vigilância empírica aberta à evidência dos conteúdos visíveis. O olho torna-se o depositário e a fonte da clareza; tem o poder de trazer à luz uma verdade que ele só recebe à medida que lhe deu à luz" (FOUCAULT, 1998, p. 11).

O encerramento da verdade biomédica na objetividade da percepção visual não se restringiu ao olho nu e não se limitou à sua acuidade natural. A esse sentido foi acrescida uma série de técnicas e tecnologias que permitiram ter acesso a pontos de vista, ângulos e grandezas impensáveis, ainda que de forma intermediada. Não obstante o superdimensionamento da visão, que permitiu que o olhar alcançasse níveis antes impensáveis, essa focalização restringiu nossa percepção, negou a importância dos demais sentidos para a compreensão do outro, mais que isso, negou a influência do invisível no processo de adoecimento e sofrimento.

A expropriação do saber-de-si imposta na relação médico-paciente, fundamentada na racionalidade biomédica, é um forte empecilho à produção da saúde. Como apontam Lacerda e Valla (2003), a qualidade da relação 
médico-paciente é fundamental à cura e ao cuidado em saúde. A qualidade dos vínculos, a satisfação durante o processo e a comunicação estabelecida são elementos fundamentais. O usuário

reclama não da falta de conhecimento tecnológico no seu atendimento, mas sim da falta de interesse e de responsabilização dos diferentes serviços em torno de si e do seu problema. Os usuários, como regra, sentem-se inseguros, desinformados, desamparados, desprotegidos desrespeitados, desprezados (MERHY, 2003, p. 83).

Para ampliar essa prática "procedimento centrada" (MERHY, 2003) e inserir o outro como sujeito portador de história, de valores, é preciso aguçar os ouvidos, apurar todos os sentidos, superar as limitações do olhar, para o que esse sujeito, sabedor de si, tem a dizer e a expressar. $\mathrm{O}$ cuidar exige essa abertura ao outro, "[...] entrar em sintonia com, auscutar-lhes o ritmo e afinarse com ele" (BOFF, 2003, p. 96).

No entanto, algumas questões insistem: a partir de certa "racionalidade prática", isto é, de uma busca por caminhos que orientem as escolhas e avaliações sobre o "que fazer" nas ações de saúde, que critérios poderão nos guiar acerca das ações a serem implementadas? Como interferir? Quando interferir? Quais estratégias privilegiar?

Estamos afirmando que os modos de operar em saúde não estão definidos a priori. Ao contrário, eles se constroem no processo, não têm caráter teleológico. É no concreto da experiência, na situação de trabalho, considerando a dinamicidade desses processos, com suas variabilidades, seus vazios de normas, ${ }^{2}$ que inventamos formas de operar nos serviços de saúde. Manter-se restrito a rígidas prescrições sobre o que deve ser feito inviabiliza encontros intersubjetivos reclamados no cuidado à saúde, uma vez que pauta o encontro a partir de absolutizações e generalizações que o precedem, não favorecendo seu caráter processual e inventivo. Ousamos dizer, ainda, que se trata de pensar num "cuidado virtual" " que demanda atualização aberta ao devir e ao compartilhamento. Oliveira et al. (2005, p. 693) propõem que:

a intervenção técnica se articula verdadeiramente como um Cuidar quando o sentido da intervenção passa a ser não apenas o estado de saúde visado de antemão, nem somente à aplicação mecânica das tecnologias disponíveis para alcançar este estado, mas o exame da relação entre finalidades e meios e seu sentido prático, conforme um diálogo o mais simétrico possível entre profissionais e usuários dos serviços.

Assim, tomar o cuidado como atividade de trabalho, é afirmar uma dimensão real que nos remete a um inacabamento não só conceitual, mas, principalmente, a um inacabamento subjetivo e dos seus modos de operar no curso da ação de cuidar. O cuidado nos remete sempre a uma dimensão do "comum", do construído junto com o outro. O cuidado é sempre uma construção coletiva. Conforme Ayres 
(2001, p. 71), ainda que passe pelas competências e tarefas técnicas, cuidar não se restringe a elas, "cuidar da saúde de alguém é mais que construir um objeto e intervir sobre ele", aponta a construção de projetos e, por isso, é fundamental, no ato de cuidar, apreender quais projetos de felicidade estão em jogo (AYRES, 2001).

Ayres (2007, p. 54) ainda adverte para o fato de que um projeto de felicidade se refere à "totalidade compreensiva na qual adquirem sentido concreto as demandas postas aos profissionais e serviços de saúde pelos destinatários de suas ações". Considera que os projetos de felicidade passam a ser referência para a construção das avaliações sobre os efeitos produzidos com as ações de saúde, seja no seu planejamento, seja na sua execução, seja na sua avaliação. A noção de projeto envolve, aqui, uma compreensão da situação existencial humana que é a de um "estar lançado", uma existência que se constrói em e a partir de diversas condições predeterminadas e determinantes da vida humana, não se refere a um projeto no sentido da definição de tarefas, recursos e prazos para o alcance de determinadas finalidades, mas, sim de "uma temporalidade não-linear, nãocumulativa, a uma própria temporalização plástica. Isto é, uma compreensão de passado, futuro e presente como experiências co-existentes e, em sua co-existência " (AYRES, 2007, p. 55), pelo modo como construímos nossa existência. O autor nos fala de um projeto de felicidade que não está definido a priori, mas que se efetiva no curso da experiência dos diferentes encontros que fazemos na vida, com outras pessoas, com idéias, valores, princípios.

Uma busca de felicidade, portanto, que se efetiva, necessariamente, no plano do coletivo, plano de co-engendramento de indivíduos e de mundos, de modos de trabalhar, modos de subjetivar e de gerir o trabalhar. É na dimensão concreta das práticas que este coletivo se configura, também, como plano ético-político, desdobrando-se numa construção em rede. A partir das práticas concretas, constitui-se um mundo comum. O coletivo, portanto, como plano e não como reunião de indivíduos. Uma política do coletivo que se afirma como funcionamento em rede, necessariamente, dialógica (BARROS; BENEVIDES, 2007). Projeto de felicidade, portanto, invariavelmente coletivo, uma vez que se efetiva no fluxo do tempo, alia forças do impessoal e requer relação com os outros. Impessoal como esfera que não pertence aos sujeitos em si e sim a um patrimônio de dimensão transversal, de um plano de conexões transversais, entre humanos, entre humanos e normas, lugar, portanto, das forças de todos e de ninguém, razão pela qual todo ser se torna em efeito de um agenciamento coletivo.

Fazendo uma derivação da proposta de Ayres (2007) sobre um projeto de felicidade como projeto para práticas de cuidado em saúde, diríamos que tais práticas se constituem como práticas humanizadas na direção apontada, na medida em que o viver humano se caracteriza como resistência, no seu duplo sentido de recusa e de criação, a toda situação de heterodeterminação. Nas ações de cuidado sempre estão presentes uma negociação entre as prescrições da atenção e as normas dos sujeitos singulares, que são a todo tempo redefinidas. A proposição de um projeto de felicidade nos parece fértil para este debate sobre um cuidado humanizado que toma o humano não a partir de um homem abstrato, um metro padrão que definiria uma natureza humana; mas da reinvenção de uma nova hu- 
manidade como tarefa inconclusa, o que só é possível com um trabalho constante de produção de outros modos de vida, de novas práticas de saúde, de outros modos de cuidar, indissociáveis dos modos de gestão atualizados nos serviços de saúde.

Como podemos, então, lidar com essa noção de projeto de felicidade no cotidiano de nossas práticas de saúde, uma vez que não se trata de qualquer forma de "planejamento"? Projeto de felicidade que nos fala de uma ética do cuidado como estética da existência, pensando um modo artístico, uma poética da atividade de cuidar, quando se misturam poesia, tecnologia, vida e movimento, de forma a escapar das estratégias de subjetivação definidas pelo modelo biomédico. Cuidado, portanto, como obra, processo, sempre aberta a novas composições em que a plasticidade da vida torna-se aliada da invenção de novos modos de existência. Trata-se de um empreendimento poético, que nos interessa pela "acontecimentalização" que, para Foucault (1998), diz de um procedimento de desnaturalização e ruptura. "Acontecimentalizar" no cuidado em saúde é perturbar as verdades que habitam o discurso biomédico hegemônico, uma operação por meio da qual as formas instituídas (e muitas vezes cristalizadas) se desmancham cedendo lugar ao estranho, ao que nos provoca, ao "jamais vu" (AMADOR, 2007, p. 81). "Acontecimentalizar" é atualizar virtualidades das ações do cuidado, "cuidado virtual".

Essa proposta tem o sentido de considerar a participação ativa dos sujeitos e o espaço do diálogo no cuidado em saúde como um espaço de reinvenção de modos de ser, modos de se relacionar com os outros, modos de se construir projetos de felicidade.

A torção proposta neste texto está marcada por um tensionamento com um modo de cuidar pautado no paradigma biomédico, problematizando-o. Não se trata de negar que esse processo já esteja em curso, mas também é inegável que os desafios que esse giro impõe não é dos mais fáceis. Diríamos que se trata de um projeto aberto, em construção e, exatamente, por não ser teleológico, nos convoca a fazer experimentações no curso das atividades de cuidado de forma a acionar um processo de criação dessas práticas e também de modos de existência dos profissionais de saúde e dos usuários.

\section{INCLUINDO O CUIDADO NAS PRÁTICAS DE SAÚDE: A IMPORTÂNCIA DO CONVERSAR}

A preferência de manter-se focado na doença ou em um órgão específico e de interagir mais com resultados de exames do que com informações trazidas pelos pacientes indica uma concepção de clínica que vamos denominar de "restrita" ou, como propõe Campos (2003), uma clínica degradada, em contraposição à proposta de uma clínica ampliada.

Campos (2003, p. 54) propõe uma reforma da clínica moderna que deve "assentar-se sobre um deslocamento da ênfase na doença para centrá-la sobre o sujeito concreto, no caso portador de alguma enfermidade", que ele nomeia de Clínica do Sujeito. Considera que existem três clínicas: uma clínica oficial, que é limitada, uma vez que se responsabiliza pela enfermidade e não "pela pessoa do enfermo"; uma clínica degradada, porque pautada pelos interesses econômicos e 
numa racionalidade do tipo instrumental ou estratégica que perde sua potencialidade conceitual e também sua "oportunidade de resolver problemas de saúde" (CAMPOS, 2003, p. 60); e uma clínica ampliada, que seria a clínica do sujeito, que inclui a doença, o contexto e o próprio sujeito e, segundo Campos (2003, p. 65), teria o desafio de "passar do campo das certezas, das regularidades mais ou menos seguras, ao campo da imprevisibilidade radical da vida cotidiana", o que implica uma clínica que demanda trabalho em equipe multiprofissional. Aqui, então, retoma-se a diretriz da clínica ampliada segundo a qual a conversa, os processos dialógicos são o caminho.

Evidentemente não se trata, aqui, de um diálogo como mero recurso para obtenção de informações "requeridas pelo manejo instrumental do adoecimento, forma de produzir uma narrativa estruturada segundo esse interesse, que é o modelo típico da anamnese clássica" (AYRES, 2007, p. 58), mas como produção de compartilhamentos. Não basta, nesse caso, apenas fazer o outro falar sobre aquilo que o profissional de saúde considera relevante saber para que o processo terapêutico se efetive. É preciso, principalmente, ouvir o que o outro, que demanda o cuidado, mostra ser indispensável. É preciso que ambos saibam para que seja possível a utilização dos recursos técnicos existentes a serviço dos procedimentos necessário para a produção de saúde. O diálogo nas práticas de cuidado baseadas em perguntas como: você cumpriu as prescrições feitas? Tomou a medicação? Fez a dieta?, indica uma postura autoritária, que denota muito mais uma preocupação com ser obedecido do que com o sujeito e sua historia, sua vida. É preciso estar atento a esses fluxos de afetos que viabilizam uma relação dialógica, uma efetiva troca intersubjetiva, que afirma autonomia e protagonismo dos sujeitos, colocando em questão práticas de especialismos que desqualificam os saberes que os sujeitos têm dessa dinamicidade saúde-doença em seu corpo. Práticas de cuidado, portanto, que focalizem e priorizem as expectativas daqueles que procuram os serviços de saúde. Nesse processo, vínculo e afetos são ingredientes indispensáveis.

Mas insistimos numa questão: como desenvolver uma ética do cuidado nas ações de saúde? A título de sugestão para que esse debate se amplie, consideramos que a prática do cuidado, conforme postulado por Foucault (1999), pode abrir linhas interessantes para uma cartografia da ética do cuidado em saúde. Seus estudos indicam a importância do cuidado de si, baseado em práticas de liberdade, que nos coloquem nos limite das relações de poder, uma proposta ética que recusa e não permite que tais relações se desequilibrem, tornando-as domínio. Assim o fazendo, o cuidado de si é, simultaneamente, cuidado com o outro, afastando-se de um fechamento em si mesmo, numa tentativa de mover-se na coletivização da liberdade, sem subtrair-lhe as chances de escolha (AMADOR, 2007). Cuidado de si que tem o sentido de um voltar-se a si mesmo, não como prática narcísica, uma vez que não guarda relações com um fascínio por si, mas como prática que estabelece uma relação estética e ética consigo mesmo para resistir ao poder que assujeita e normaliza. Um cuidar de si coextensivo ao ato de viver. "Cuidar de si para converter-se ao extravio de si, indo em direção a si próprio para perder-se" (AMADOR, 2007, p. 87). Cuidado de si como cuidado da alma, como espaço para o pensamento, para a reflexão, para o diálogo, para o 
encontro com o semelhante. Uma relação dialógica que é, ao mesmo tempo, um olhar que se lança sobre o outro e uma maneira de se oferecer ao olhar do outro por meio do que lhe é dito sobre si mesmo.

Também Maturana (2001, p. 75) propõe que “ as preocupações éticas, a responsabilidade e, a liberdade tem lugar apenas enquanto alguém pode ver o outro, a si mesmo e as conseqüências das ações de alguém nos outros, ou em si mesmo e age de acordo com a decisão entre querer, ou não, essas conseqüências". Assim, cuidar de si implica na avalição constante da relação com os outros e com o mundo. Para Maturana (1998, 2001), tanto nosso bem-estar como nosso sofrimento físico e psíquico dependem do conversar. As ações humanas estabelecemse, necessariamente, no conversar, "o ser humano se realiza no conversar como entrecruzamento da linguagem com o emocionar que surge com a linguagem" (MATURANA, 1998, p. 100). Para Maturana (2001), a linguagem não se restringe apenas à troca de informações, à fala, ou a algum gesto ou postura particular. Ela desencadeia mudanças estruturais e modulações mútuas em seus participantes.

$\mathrm{O}$ ato de conversar que se fundamenta num processo de afetação mútua e assume um papel estratégico porque exige uma relação entre dois sujeitos. $\mathrm{O}$ conversar, nessa direção, permite o fluir da ação de forma que a vida continue em seu processo dinâmico. É necessário superar o monólogo em direção ao diálogo, e aí não só no que diz respeito aos pacientes/usuários, mas também em relação aos diferentes profissionais de saúde. Nessa direção, Teixeira (2003) afirma que a substância do trabalho em saúde é a conversa. Assim a qualidade do "conversar" que se estabelece nos serviços de saúde passa a ser foco de análise.

É fundamental que as relações estabelecidas, as técnicas, procedimentos e rotinas presentes nos serviços de saúde não impermeabilizem o espaço da troca, de forma que as relações estabelecidas sempre possam desencadear uma transformação mútua nas dinâmicas corporais de quem delas participa. Que a ideia de patthos, fundamental a Medicina, volte a ser compreendida não apenas como doença física, mas também como paixão e que o seu entendimento seja relativo tanto "à perturbação do corpo como ao movimento involuntário da alma" (FOUCAULT, 1999, p. 59). Assim, não cabe apenas encontrar a causa da dor, mas entendê-la e compartilhá-la. Sentir o outro e abrir-se às suas paixões, aos seus valores nesse encontro, eis o princípio ético do cuidado.

\section{Algumas considerações acerca do Cuidado como ética em SaÚde}

Dessa forma, o cuidado não corresponde a mais um procedimento técnico específico, não há fórmulas que ensinem a cuidar. Esse termo é, antes, uma referência ética que deve enraizar todas as práticas em saúde e construídas por enfermeiros, médicos, psicólogos, assistentes sociais, técnicos de enfermagem, agentes comunitários de saúde e os demais profissionais da área. "O cuidar é mais que um ato; é uma atitude. Portanto, abrange mais que um momento de atenção, de zelo e de desvelo. Representa uma atitude de ocupação, preocupação, de responsabilização e de envolvimento afetivo com o outro" (BOFF, 2003, p. 33). 
O cuidado como princípio emerge, então, como elemento transversal que se faz na intercessão das diferentes disciplinas que subsidiam as práticas em saúde articulando-as, numa direção ético-política transdisciplinar. Com isso, ele assume uma posição de importância inquestionável nos serviços de saúde na medida em que permite a superação, ou pelo menos a minimização, de um de seus grandes obstáculos: a negação ou desqualificação do outro.

Essa vocação irresistivelmente dialógica dos arranjos tecnológicos do cuidado em saúde orientado por essa direção ético-política que afirmamos corrobora a impossibilidade de basear tais práticas em qualquer critério normativo anterior do "que deve ser feito?". Ao longo deste artigo, propomos uma torção na questão "do que fazer" para o "como fazer".

O curso de um diálogo pertence tanto a seus interlocutores quanto estes the pertencem. Enquanto há diálogo é porque há mais o que saber, é porque há mais a se dizer. Nessa direção, "juntos com" afirmamos que a produção dessa forma de cuidado não se separa dos modos de produção de subjetividade, não há como produzir esse giro se não se investir na produção de outros modos de ser trabalhador da saúde, outros modos de trabalhar, pautados na co-gestão dos processos de trabalho, portanto, nas diferentes dimensões com as quais os profissionais de saúde estão comprometidos nas ações de cuidado. Muitos são os desafios quando estamos lidando com a defesa da vida. Desafios que nos colocam diante de novas questões que demandam novas respostas que impõem a necessidade de mudança de rumos.

Um cuidado como trabalho clínico que visa ao sujeito, à dinamicidade dos processos de saúde e doença, à família e seu contexto, ao entorno, aos valores, sendo seu objetivo aumentar a autonomia dos sujeitos, produzir saúde. Isso não se efetiva sem um trabalho em equipe que se move, que se faz coletivamente, que "muda ao durar e se reinventa pelos encontros que o constituem" (BARROS; BENEVIDES, 2007, p. 76). Um trabalho como co-engendramento - que constrói vínculos entre os diferentes sujeitos implicados no processo e elabora projetos terapêuticos que sejam "projetos de felicidade" (AYRES, 2007).

Entender as práticas de cuidado como clínica ampliada, como clínica aberta, é estabelecer um compromisso radical com o sujeito visto como singular, assumindo responsabilidades no processo terapêutico, afirmando a intersetorialidade em saúde e tendo a dimensão dos limites dos saberes especializados. Dessa forma, afirmamos uma perspectiva transdisciplinar, que rompe com os especialismos desqualificadores e busca outros conhecimentos-saberes, assumindo, enfim, um compromisso ético que não reduz o sujeito à doença.

Nessa direção, a escuta é uma importante estratégia do cuidado, o que significa valorizar todo o relato do usuário, mesmo que nos pareça não ter relação direta com o tratamento. Escutar é ajudá-lo a reconstruir a história do seu processo de adoecimento e as diferentes articulações que estabelece com outros planos de sua vida. É a doença compreendida e correlacionada com a vida dos sujeitos. 
Mas como operar tal clínica? Esse modo de tomar o cuidado em saúde nos remete a uma concepção de clínica que não se reduz ao movimento do inclinar-se sobre o leito do doente da noção grega de klinikos - de kline, leito, repouso, de klino inclinar, dobrar - mas, principalmente, como clinamen, que é experiência de desvio, que faz bifurcar um percurso de vida na criação de novos territórios existenciais. Assim, a clínica, conforme propomos neste texto, mais do que uma atitude de acolhimento de quem demanda tratamento baseada numa noção adaptacionista, utilitária ou ortopédica, entende o cuidado como produção de desvio (clinamen), de desestabilização (PASSOS; BENEVIDES, 2001).

As práticas dessa clínica ampliada, dessa clínica do cuidado, situam-se no plano da ética, entendida como grau de abertura à processualidade e à alteridade, e direcionam as nossas escolhas a partir daquilo que favorece o conviver, que favorece outros modos de estar junto nos serviços de saúde (GOMES; SILVA; PINHEIRO; BARROS, 2007). Uma clínica que pressupõe estar junto com o outro, entendendo-o como legítimo. Esta clínica (clinamen) produz desvio na medida em que coemergem novos sujeitos nessa relação, novos trabalhadores e novos usuários desse encontro, do encontro dos corpos e afetos e das modulações mútuas. Cada encontro transforma os modos de agir no sistema de saúde, seus modos de ser, trabalhar, adoecer e viver.

\section{Notas}

Entropia pode ser entendida, no seu sentido original relativo à segunda lei da termodinâmica que afirma que todo sistema natural, quando deixado livre, evolui para um estado de desordem máxima. ${ }^{2}$ Refere-se à insuficiência de normas e prescrições para a realização do trabalho, que exige a mobilização do trabalhador na criação de novas normas.

${ }^{3}$ Expressão derivada da idéia de Trabalho Virtual apresentada por Amador (2007), em que faz referência aos virtuais do trabalho. Virtualidade como plano do que ainda não ganhou existência, que se atualiza na atividade de trabalho real, que, em nosso caso, é a atividade do cuidar. Trata-se de um plano que coexiste com o atual, em circuito com ele. Na formulação de Amador (2007, p. 35), o trabalho virtual é "aquele ligado às forças que, como virtuais, entram em curso de atualização podendo chegar ao trabalho real [...] refere-se às forças que sempre aguardam atualização na experiência do trabalho".

\section{REFERÊNCIAS}

ALMEIDA FILHO, N. Transdisciplinaridade e Saúde Coletiva. Ciência e Saúde Coletiva, Rio de Janeiro, v. 2, n. 1/2, p. 63-72, 1997.

AMADOR, F. S. Olhos que buscam: por entre prisões da imagem, imagens da prisão. 2007. Projeto de qualificação (Doutorado) - Universidade Federal do Rio Grande do Sul, Porto Alegre, 2007.

AYRES, J. R. C. M. Sujeito, intersubjetividade e práticas de saúde. Ciência e Saúde Coletiva, Rio de Janeiro, v. 6, n. 1, p. 63-72, jan./jun. 2001.

AYRES, J. R. C. M. Uma concepção hermenêutica de saúde. Physis, Rio de Janeiro, v. 17, n. 1, p. 43-62, jan./abr. 2007. 
BARROS, M. E. B.; BENEVIDES, R. A potência formativa do trabalho em equipe no campo da saúde. In: PINHEIRO, R.; BARROS, M. E. B; MATOS, R. A. (Org.). Trabalho em equipe sob o eixo da integralidade: valores, saberes e práticas. Rio de Janeiro: ABRASCO, 2007. p. 75-84.

BENEVIDES, R.; PASSOS, E. A humanização como dimensão pública das políticas de saúde. Ciência e Saúde Coletiva, Rio de Janeiro, v. 10, n. 3, p. 561571, jul./set. 2005.

BOFF, L. Saber cuidar: ética do humano - compaixão pela terra. 9. ed. Petrópolis: Vozes, 2003.

BOLTANSKI, L. As classes sociais e o corpo. 2. ed. Rio de Janeiro: Graal, 1984.

BRASIL. Ministério da Saúde. Secretaria-Executiva. Núcleo Técnico da Política Nacional de Humanização. HumanizaSUS: Política Nacional de Humanização: a humanização como eixo norteador das práticas de atenção e gestão em todas as instâncias do SUS. Brasília, DF: Ministério da Saúde, 2004.

CAMARGO JÚNIOR, K. R. Biomedicina, saber e ciência: uma abordagem crítica. São Paulo: Hucitec, 2003.

CAMPOS, G.W. Saúde paidéia. São Paulo: Hucitec, 2003.

CANGUILHEM, G. O normal e o patológico. Rio de Janeiro: Forense Universitária, 2000.

CAPONI, S. Georges Canguilhem y el estatuto epistemológico del concepto de salud. História, Ciências, Saúde, Rio de Janeiro, v. 4, n. 2, p. 287-307, abr.jun. 1997.

COElHO, M. T. Á. D.; AlmeIdA FILhO, N. de. Conceitos de saúde em discursos contemporâneos de referência científica. História, Ciência e SaúdeManguinhos, Rio de Janeiro, v. 9, n. 2, p. 315-333, abr.jun. 2002.

DEJOURS, C. Por um novo conceito de saúde. Revista Brasileira de Saúde Ocupacional, São Paulo, v. 14, n. 54, 1986.

DELEUZE, G. Do arquivo ao diagrama. In: . Foucault. São Paulo: Brasiliense, 1988. p. 13-53

FOUCAULT, M. O nascimento da medicina social. In: . Microfísica do poder. Rio de Janeiro: Graal, 1995. p. 79 - 98. 
FOUCAULT, M. O nascimento da clínica. 5. ed. Rio de Janeiro: Forense Universitária, 1998.

FOUCAULT, M. História da sexualidade 3: o cuidado de si. 6. ed. Rio de Janeiro: Graal, 1999.

FOUCAULT, M. Aula de 17 de março de 1976. In: . Em defesa da sociedade. São Paulo: Martins Fontes, 2002. p. 285-315.

GOMES, R. S.; SILVA, F. H; PINHEIRO, R.; BARROS, M. E. B. Integralidade como princípio ético e formativo: um ensaio sobre os valores éticos para estudos sobre o trabalho em equipe em saúde. In: PINHEIRO, R.; BARROS, M. E. B; MATOS, R. A. (Org.). Trabalho em equipe sob o eixo da integralidade: valores, saberes e práticas. Rio de Janeiro: ABRASCO, 2007. p. 19-36.

LACERDA, A.; VALLA, V. Homeopatia e apoio social: repensando as práticas de integralidade na atenção e cuidado à saúde. In: PINHEIRO, R.; MATTOS, R. A. (Org.). Construção da Integralidade: cotidiano, saberes e práticas em saúde. Rio de Janeiro: ABRASCO, 2003. p. 169-196.

LUZ, M. T. Políticas de descentralização e cidadania: novas práticas de saúde no Brasil atual. In: PINHEIRO, R.; MATTOS, R. A. (Org.). Os sentidos da integralidade na atenção e no cuidado à saúde. Rio de Janeiro: ABRASCO, 2001. p. 17-38.

LUZ, M. T. Novos saberes e práticas em saúde coletiva: estudo sobre racionalidades médicas e atividades corporais. São Paulo: Hucitec, 2003.

MACHADO, R. Introdução: por uma genealogia do poder. In: FOUCAULT, M. Microfísica do poder. Rio de Janeiro: Graal, 1995. p. 7-23.

MATURANA, H; VARELA, F. A árvore do conhecimento: as bases biológicas do entendimento humano. Campinas: Psy II, 1995.

MATURANA, H. Linguagem e realidade: a origem do humano. In: .$D a$ biologia à psicologia. 3. ed. Porto Alegre: Artes Médicas. 1998. p. 95-102.

MATURANA, H. Formação humana e capacitação. Petrópolis: Vozes, 2000.

MATURANA, H. Ontologia do conversar. In: . A ontologia da realidade. Belo Horizonte: UFMG, 2001. p. 167-181

MERHY, E. E. O ato de cuidar: a alma dos serviços de saúde. In: BRASIL. Ministério da Saúde. Caderno de textos do projeto-piloto VER-SUS Brasil. Brasília, DF: Ministério da Saúde, 2003. p. 80-99. 
NORIEGA, M. Organización laboral, exigencias y enfermendad. In: LAURELL, A. C. (Org.). Investigacion sobre la salud de los trabajadores. Washington: OPS, 1993. p. 167-188. Série Paltex.

OLIVEIRA, P. S. Caminhos de construção da pesquisa em ciências humanas. In__ (Org.). Metodologia das ciências humanas. 2. ed. São Paulo: Hucitec, 2001. p. 17-26.

OLIVEIRA, L. A. et al. Humanização e cuidado: a experiência da equipe de um serviço de DST/Aids no município de São Paulo. Ciências e Saúde Coletiva, Rio de Janeiro, v. 10, n. 3, p. 689-698, jul./set. 2005.

PASSOS, E.; BENEVIDES, R. Clínica e biopolítica na experiência do contemporâneo. Revista de Psicologia Clínica PUC/RJ, Rio de Janeiro, v. 13, n. 1, p. 89-100, jan./jun. 2001.

SANTOS FILHO, S.B.; BARROS, M.E.B.; GOMES, R.S. Política Nacional de Humanização como política que se faz no processo de trabalho em saúde. Interface-Comunicação Saúde, Educação, Botucatu, v.13, supl.1, p. 603-613, 2009.

TEIXEIRA, R. R. Acolhimento num serviço de saúde entendido como uma rede de conversações. In: PINHEIRO, R.; MATTOS, R. A. (Org.). Construção da integralidade: cotidiano, saberes, e práticas em saúde. Rio de Janeiro: UERJ, IMS: ABRASCO, 2003. p. 89-112.

Recebido em: 20 de fevereiro de 2011 Aceito em: 24 de outubro de 2011 
